\title{
EFFECTS SIMULATING FATIGUE IN SIMPLE REACTIONS
}

\author{
From the Psychological Laboratory of McLean Hospital \\ F. I. WELLS, Ph.D., In Charge \\ C. M. KELLEY, M.D., Associate \\ GARDNER MURPHY, A.M., Assistant
}

I. The time of the simple reaction process has generally been regarded as very resistant to fatigue. Observations by Cattell have given the chief ground for this view, but his classical experiments ( $I$ ) on this subject hardly show such absence of fatigue loss as to justify regarding the question as closed. There were studied discriminative reactions to light, letters and other associations, as well as simple reactions to light and sound. Observations covering periods of about i6 hours were made with two subjects. Signs of fatigue are variable, but certainly present in various series. The final light reaction series for Subject $C$ is $\mathbf{1 2 2}$ per cent. of the initial reactions series; in Subject $B$ this fatigue effect is hardly traceable. Both subjects show moderately increased times for letters, and for the associations the final time averages in $B$ I3 I per cent. of the initial, for $C$ II3 per cent. Simple reaction time to sound cannot be said to show a loss in either subject. It is observable that variability of reaction times does not change in proportion to the length of the reaction times themselves; also that there is generally more loss on the visual side, where the chances of sensory fatigue are greater; also that there is more fatigue loss in the more automatic functions, where it is less offset by practise.

2. In the series reported by Bettmann (2), of 1,000 (apparently to sound) choice reactions made in two hours, the score for the final fifth is 108 per cent. of the initial fifth. Woodrow (3) reports shorter reaction times obtained at the end of an hour's reaction time work of similar character to the present,

1 As of August 1, 1920. 
but under conditions more generally stimulating to the subject.

The present experimental facts are soon told. When $2 \times 6$ reactions are taken under the conditions of these experiments (4), the reaction time in the second I08 reactions averages close to I05 per cent. of that in the first 108, as appears in the following figures:

Per Cent. which the Reaction Time Score in the Second Half of the ExperiMent is of the Score in the First Half

\begin{tabular}{|c|c|c|c|}
\hline Subjects & A-group (13 Persons) & $K$ & $w$ \\
\hline 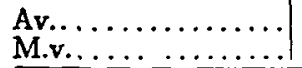 & $\begin{array}{r}104.9 \\
4.9 \\
\end{array}$ & $\begin{array}{r}105.1 \\
4.8 \\
\end{array}$ & $\begin{array}{r}106.3 \\
3.5 \\
\end{array}$ \\
\hline
\end{tabular}

3. Variability within each unit reaction-series (27 reactions) is indicated by the per cent. which its upper quartile is of its median. This figure is termed the 'quartile ratio.' It is observed that while the central tendencies are longer in the second half (par. 2), this lengthening is unaccompanied by corresponding increase in the quartile ratios. These are quite stable, as follows:

Per Cent. which the Quartile Ratios of the First Half are of the Quartile Ratios of the ENTIRE EXPERIMENT

\begin{tabular}{c|c|c|c}
\hline Subjects & A.group & $K$ & $W$ \\
\hline Av.................... & 49.9 & 50.2 & 49.8 \\
M.v... & 1.2 & .7 \\
\hline
\end{tabular}

4. It runs counter to the weight of evidence to suppose the loss due to actual effort in the repeated reactions themselves. The series last some forty minutes each, and there is a recovery period between single observations of about eleven seconds. Appeal can hardly be taken to exhausting character of the work itself.

5. More suitable interpretation is found in certain special conditions of the work. The room in which it takes place is considerably darkened, to permit reading of a galvanometer scale. The subject's only sense stimuli incidental to the experiment are the closing of the experimenter's key for the get-ready signal, the get-ready signal itself, the stimulus for reaction, and whatever noise or other disturbance the subject 
makes in his own responses. The galvanometer chronoscope operates entirely without noise. The average interval between stimuli is slightly over II seconds, which makes the reactions seem very discontinuous. As an experiment progresses, the subject is apt to show signs of increasing somnolence, yawning or stretching, etc. The writer $(W)$, found it the most eninuyant of experiments, as the doctor of physick his own draught, until it became possible to perform it 'from the spinal cord.' Part of this 'logeyness' induced by the conditions, seems to be a slightly increased refractoriness to the simple reaction process. It is well to note that while the reactions become definitely longer, they do not become more variable (par. 3). The loss does not involve a diminution of attentional control, as expressed in tendency of attention to occasional lapse. It is rather an upward thrust of the whole distribution.

6. There appears in these experiments a decrease in functional efficiency under continued exercise of the function. The question if fatigue is a term properly applicable to such decrease leads into a somewhat casuistical discussion. Thorndike (5) has regarded it as a characteristic of fatigue, that it shall be a condition improvable by rest. It is improbable that the phenomena meet this criterion, as rest is ordinarily conceived. A lessening or temporary cessation of the experimental work, or a further lessening of the already slight general stimulation which the environment of the subject affords, would be likely to further decrease his efficiency, or abolish it entirely by putting him to sleep. The 'rest' that would cure this decreased efficiency would be some relief from the rather depressing experimental conditions described.

7. The writers favor regarding this slowing of reaction time as a fatigue effect, under the concept of fatigue as a name including all influences by which the continuance of a task tends to decrease its efficiency. Accumulation of fatigue toxins as result of either mental or physical overexertion seems to be here ruled out. Secondary effects of disagreeable sensations from such exertions seem also ruled out. The effective 
factor is rather a 'monotony,' and its result, a raising of the reaction threshold.

8. It may be asked if there is any difference of sound and light stimuli in this respect, as these sensations differ so much in their own fatigue phenomena. A generally negative answer is implicit in the findings of a previous paper. In both halves of the experiment, the sound-light ratios (per cent. which the light time is of the sound time) are similar for the A-group of thirteen subjects and for Subject $W$. In Subject $K$ the sound-light ratios are clearly less in the second half; that is, the sound reaction has lost more than the light. This is the opposite of what would be expected from a sensory fatigue effect.

9. A similar question may be asked regarding the two different prestimulus (get-ready) intervals employed; whether the monotony and consequent 'logeyness' have the more effect on a one-second or a three-second prestimulus interval. As expressed in the A-group, the general effect is that the monotony is especially unfavorable to the longer, threesecond, prestimulus interval. The average difference in favor of the one-second interval in the second half, is the same for sound and light. The differential effect on the prestimulus intervals does not appear in $K$ and $W$, there being substantial equality throughout their records. This should be taken in connection with the presumably lesser conscious attention in these subjects during their repeated series. In $W$ especially, the process was little short of automatic, with no conscious attention to the interval employed.

For the A-group, the longer times in the second half are essentially due to the results with the three-second interval. The difference for the one-second interval is hardly significant. The figures are as follows, in which there again appears the tendency to smaller variations in the results for light:

Per Cent. whice the Scores for the Two Prestimulus Intervals in the Second Half are of Their Scores in the First Half; (A-Group Ondy)

\begin{tabular}{|c|c|c|c|c|}
\hline & Sound, $x^{\prime \prime}$ & Sound, $3^{\prime \prime}$ & Light, $z^{\prime \prime}$ & Light, $3^{\prime \prime}$ \\
\hline 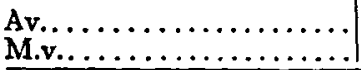 & $\begin{array}{r}102.7 \\
7.3\end{array}$ & $\begin{array}{r}108.1 \\
11.5\end{array}$ & $\begin{array}{r}101.2 \\
5.9\end{array}$ & $\begin{array}{r}107.0 \\
3.9\end{array}$ \\
\hline
\end{tabular}


Io. In respect to the general disfavoring in the A-group of the longer interval by the monotony, the indication is that the 'fatigue' of monotony makes it little if at all harder to rouse the attention (to a one-second interval), but rather harder to hold it (to a three-second interval). This is the early monotony effect. With the subjects accustomed to experimental conditions, $K$ and $W$, the monotony effect is more evenly distributed to both prestimulus intervals.

II. It is a fate of concepts either to die barren, or to perish in bringing forth new ideas. 'Secondary dementia,' the Freudian sexuality, the Binet intelligence, herein bear the better part. A similar destiny perhaps awaits the concept of fatigue. The fundamental implications of the term are two: continued subjection to certain working conditions, and decreased effectiveness of some response. There are various formulations of how the first of these brings about the second. They are given in terms of toxins, reflex inhibitions, refractory phase. Monotony has also been cited as a factor in fatigue effects. The word implies a feeling of disagreeableness resulting from sameness. It is reasonable to regard this disagreeableness as secondary to an increasing difficulty resulting from sameness, as well as from general lack of environmental stimulation, and to include it in a broad conception of 'refractory phase.' It may be noted that saying the reaction time is increased in the second half of the experiment is the same as saying that it requires a greater stimulus in the second half to keep the reaction time at its former level; the reaction threshold is by so much raised.

12. In sum, the present experimental conditions are such as to make the reaction times in the second half of a fortyminute experiment, average some 105 per cent. of those in the first half. These conditions, with their moderate work and ample rests pretty well exclude exhaustion in the lower nervous arcs and allow a monotony effect to appear in relatively pure form. A distinctive feature of it is selective action on the longer, three-second prestimulus interval. Again, it does not alter the variability of the reaction times, which showed some tendency to grow greater in the results 
of Cattell. The alertness aroused by the get-ready signal is not so well maintained under monotony as at the beginning, but it does not fluctuate any more under monotony.

\section{REFERENCES}

1. Catteld, J. M. Psychometrische Untersuchungen. Philos. Stud., 1886, 3, 489492.

2. BetTMAN, S. Beeinflussung einfacher psychischer Vorgānge durch körperliche und geistige Arbeit. Psychol. Arb., 1896, x, p. 157.

3. Woodrow, H. The Effect upon Reaction Time of Variation in the Preparatory Interval. Psychol. Monog., 1914, 17, pp. 55, 57.

4. Wells, F. L., Kellet, C. M., Murphy, G. Comparative Simple Reactions to Light and Sound. This Journal.

5. Thormdike, E. L. The Curve of Work. Psychol. Reo., 1912, 19, 165-194. 